

\section{INOVAR PELA LEI}

\section{A formação de uma cultura de proteção de dados a partir da nova legislação pode trazer valor agregado para as organizações.}

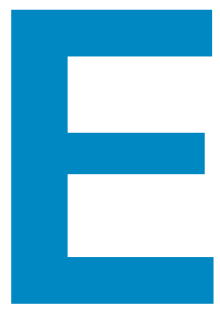

m 2017, ficou famosa a capa da The Economist com a mensagem de que o recurso mais valioso do mundo não era mais o petróleo, mas, sim, os dados. A revista inglesa ilustrava as grandes empresas de tecnologia como as estações petrolíferas que extrairiam riqueza desse novo ativo. Um ano depois, em agosto de 2018, o Brasil aprovou a sua Lei Geral de Proteção de Dados Pessoais (LGPD - Lei ${ }^{\circ}$ 13.709/2018), mesmo ano em que passou a valer o regulamento de proteção de dados na União Europeia, a General Data Protection Regulation (GDPR). Agora, em 2019, ganha força o movimento dos Estados Unidos para que o país também crie uma regulação a nível federal, depois de alguns estados, sobretudo a Califórnia, terem legislado a respeito do assunto.

Ao longo desses últimos três anos, estamos testemunhando uma verdadeira ebulição do tema e, mais especialmente no cenário nacional, estamos vivendo isso à flor da pele com uma nova lei que estabelece definitivamente as regras do jogo. É hora de dar um passo atrás, recuperar os registros do porquê e de como se gestaram leis gerais de proteção de dados pessoais. Com esse diagnóstico, pretende-se apontar possíveis tendências dessa nova agenda.

\section{OLHANDO PARA A HISTÓRIA}

Olhar no retrovisor faz com que se perceba que a demanda por regular o uso de dados pessoais em si não é nova. Viktor Mayer, professor da Universidade de Oxford, aponta que as primeiras iniciativas deram errado por tentarem domesticar a tecnologia. Logo se constatou ser impossível prescrever de antemão uma lista fechada sobre seus usos lícitos e ilícitos. Migrou-se, então, para uma abordagem focada na definição dos direitos do titular da informação, cidadãos-consumidores e deveres das organizações que processavam tais dados.

Desde a década de 1980 até hoje, os chamados princípios e práticas informacionais justos - Fair Information Practice 


\section{A nova regulação sobre dados terá possivelmente impacto muito maior do que foi a edição do Código de Defesa do Consumidor nos anos 1990, já na medida em que abraça relações de trabalho e, também, do cidadão com o setor público.}

Principles (FIPPs) - são a espinha dorsal das leis de proteção de dados pessoais. Originados no âmbito do Departamento de Bem-Estar Social dos Estados Unidos, tais princípios foram espelhados nas Diretrizes sobre Privacidade e Livre Fluxo Informacional da Organização para a Cooperação e Desenvolvimento Econômico (OCDE) e na Convenção Internacional para a Proteção de Dados do Conselho da Europa. OS FIPPs não só capilarizaram tais normas em nível global, como também demarcaram o duplo objetivo dessa empreitada regulatória: proteger os direitos e as liberdades fundamentais dos cidadãos e, ao mesmo, estimular o desenvolvimento econômico.

Já naquela época havia o diagnóstico em torno da necessidade de se estabelecer as regras do jogo para que fosse nutrida a confiança do cidadão em conceder seus dados para organizações públicas e privadas. Caso contrário, censos demográficos e técnicas de marketing ainda incipientes, que respectivamente nada mais são do que a conversão de dados pessoais em estatísticas e informações para a formulação de melhores políticas públicas e bens de consumo, seriam possivelmente represados.

O Brasil chegou atrasado, mas finalmente entrou para o rol de mais de 120 países com leis gerais de proteção de dados pessoais. Espera-se que o novo marco regulatório cumpra o seu objetivo de estimular o fluxo informacional e, com isso, o desenvolvimento socioeconômico dele dependente, conforme uma lógica de sustentabilidade entre quem produz essa matéria-prima e quem a explora.

\section{IMPACTO REGULATÓRIO E SOCIOECONÔMICO DA LGPD}

$\mathrm{O}$ adjetivo geral é aqui o elemento-chave. A LGPD vem para complementar uma série de leis setoriais já existentes no Brasil, mas que era uma regulação precária e não vocacionada para lidar com uma economia e sociedade cada vez mais movidas por dados (veja no artigo Novos direitos quais são os direitos de LGPD). Na medida em que se tem uma lei de aplicação transversal, elimina-se a assimetria regulatória antes existente por uma abordagem fragmentada. Agora todos os setores da economia estarão cobertos, e há uma peça central do quebra-cabeça regulatório que dita um mínimo de uniformidade. Com isso, garante-se segurança jurídica para que se estimule a troca de dados nas mais diferentes situações e momentos, por intermédio de um regramento e de um vocabulário de definições comuns.

Não é só, portanto, os setores de tecnologia e de internet que são afetados pela LGPD, como se poderia concluir a partir da citada capa da The Economist. Todos os outros, inclusive os mais tradicionais, terão de tratar os dados dos seus consumidores e colaboradores de acordo com a LGPD. A nova regulação terá possivelmente um impacto muito maior do que foi a edição do Código de Defesa do Consumidor nos anos 1990, tendo em vista que abraça relações de trabalho e, também, do cidadão com o setor público.

A lei adota um conceito amplo de dado pessoal: uma informação relacionada a uma pessoa identificada ou identificável. Muito além daquele conjunto de informações que nos identifica de forma direta e imediata (como nome, Registro Geral - RG, Cadastro de Pessoa Física - CPF ou biometria), também estão debaixo do guarda-chuva da LGPD aqueles dados que nos identificam de forma remota ou indireta (como apelidos, fotos, endereços de e-mail, endereços residenciais, endereços de IP, dados de geocalicazação etc.).

Os tentáculos LGPD são, portanto, enormes. É difícil imaginar em que momento não estamos trocando dados e, sobretudo, quando nossas vidas não são orquestradas com base no que um banco de dados diz a nosso respeito. Da concessão de crédito, passando pelo acesso a benefícios sociais até a timeline da rede social, todas essas atividades são automaticamente personalizadas com base nos registros que geramos. Por isso, regulações desse tipo e nesse estágio equivalem ao nosso próprio contrato social contemporâneo. 


\section{DUAS MENTALIDADES DE PROCESSO DE CONFORMIDADE À LGPD}

\begin{tabular}{|l|l|l|} 
MMA OBRIGAÇÃO LEGAL & UMA JANELA DE OPORTUNIDADE \\
Análise estanque centrada no diagnóstico de riscos. & $\begin{array}{l}\text { Análise dinâmica centrada no que } \\
\text { a organização pode gerar de valor. }\end{array}$ & $\begin{array}{l}\text { Criação de novos produtos e revisão } \\
\text { de modelo de negócio ou política pública. }\end{array}$ \\
\hline Gestão baseada em mitigação de risco. & Gestão baseada em inovação. \\
\hline Reputação com base no medo de sanções. & $\begin{array}{l}\text { Reputação com base em dar } \\
\text { mais transparência ao uso dos dados. }\end{array}$ \\
\hline
\end{tabular}

LGDP: LEI GERAL DE PROTEÇÃO DE DADOS PESSOAIS.

FONTE: ELABORADO EM COAUTORIA COM MARIA CECLILIA OLIVEIRA GOMES, AUTORA DE PARA ALÉM DE UMA OBRIGAÇĀO LEGAL: O QUE A METODOLOGIA DE BENEFÍCIOS E RISCOS NOS ENSINA SOBRE O PAPEL DOS RELATÓRIOS DE IMPACTO A PROTEÇÃO DE DADOS, 2019

\section{MUDANÇA DE CULTURA E OPORT́UNIDADES}

Apesar de uma nova regulação causar receio em relação aos custos de conformidade (o aumento do custo Brasil), a LGPD representa uma janela de oportunidade. Primeiramente, porque as organizações terão de colocar ordem na casa, pois vão precisar conhecer melhor as suas bases de dados e lhes atribuir uma finalidade específica - um dos princípios da lei. É um exercício que poderá trazer insights para se repensar o próprio modelo de negócio ou política pública e para lançar novos produtos e serviços. Em segundo lugar, porque a adequação à legislação pode melhorar a reputação da empresa, na medida em que o tratamento adequado dos dados pode ser explorado no plano de comunicação para reforçar a confiança com o titular da informação. Terceiro, porque a lei traz exigências associadas à segurança da informação no sentido não só de prevenir o vazamento de dados, mas também de remediá-lo da forma mais eficiente caso isso ocorra. Trata-se de medidas cujo saldo final pode agregar valor e competitividade a uma organização, a depender de qual mentalidade orientará o seu processo de conformidade (veja no quadro).

De forma geral, a mineração de dados, para utilizar um termo da ciência da computação, sempre procura levar a um lugar: a extração de uma informação. Essa é, também, a racionalidade por trás da nova regulação, por meio da qual a organização precisa não só conhecer os dados que possui, como também deve convertê-los em informação útil. Todo o sistema gira em torno da lógica de se criar uma trilha auditável do dado, um modelo de governança para que o cidadão e os demais agentes envolvidos enxerguem a repercussão do uso dessas informações em suas atividades econômicas e relações sociais.

A edição de uma lei é apenas o primeiro passo na formação de uma cultura de proteção de dados pessoais no Brasil. Tomando como exemplo a edição do Código de Defesa do Consumidor, nos anos 1990, demorou certo tempo para que o cidadão, os órgãos de fiscalização e os próprios agentes econômicos fizessem a lei pegar. Após quase quatro décadas, é possível dizer que a lei trouxe "civilidade" ao mercado de consumo, com produtos e serviços mais seguros. As organizações que enxergaram no novo marco regulatório uma oportunidade em agregar valor e reputação aos seus produtos até hoje colhem os frutos de sua estratégia.

Da mesma forma, aquelas que estabelecerem processos de governança de dados, investindo em capital humano e não só tecnológico, tudo isso como parte da sua missão institucional, se anteciparão e capitalizarão o processo da formação de uma cultura de proteção de dados pessoais no Brasil.

\footnotetext{
PARA SABER MAIS:

Bruno Ricardo Bioni. Proteção de Dados Pessoais: a função e os limites do consentimento, 2019. Bruno Ricardo Bioni. 18 textos para entender privacidade e proteção de dados pessoais, 2018. Bruno Ricardo Bioni. Regulação de dados é uma janela de oportunidade. Valor Econômico, 2019. Maria Cecilia Oliveira Gomes. Para além de uma obrigação legal: o que a metodologia de benefícios e riscos nos ensina sobre o papel dos relatórios de impacto à proteção de dados, 2019
}

BRUNO RICARDO BIONI > Consultor na área de proteção de dados pessoais e privacidade e professor fundador do Data Privacy Brasil > bioni@brunobioni.com.br 